\title{
Children who screen positive for autism at 2.5 years and receive early intervention: a prospective naturalistic 2-year outcome study
}

This article was published in the following Dove Press journal:

Neuropsychiatric Disease and Treatment

I September 2016

Number of times this article has been viewed

\author{
Birgitta Spjut Jansson ${ }^{1-3}$ \\ Carmela Miniscalco ${ }^{1,4}$ \\ Joakim Westerlund ${ }^{1,5}$ \\ Anne-Katrin Kantzer ${ }^{1,6}$ \\ Elisabeth Fernell' \\ Christopher Gillberg' \\ 'Gillberg Neuropsychiatry Centre, \\ Sahlgrenska Academy, Institute \\ of Neuroscience and Physiology, \\ University of Gothenburg, ${ }^{2}$ Unit of \\ Child and Adolescent Habilitation, \\ ${ }^{3}$ Department of Psychology, \\ University of Gothenburg, \\ ${ }^{4}$ Division of Speech and Language \\ Pathology, Institute of Neuroscience \\ and Physiology, University \\ of Gothenburg, Gothenburg, \\ ${ }^{5}$ Department of Psychology, \\ University of Stockholm, Stockholm, \\ ${ }^{6}$ Department of Child and Adolescent \\ Psychiatry, NU Hospital Organization, \\ Trollhättan, Sweden
}

\begin{abstract}
Background: Previous research has stressed the importance of early identification and intervention for children with autism spectrum disorders.

Methods: Children who had screened positive for autism at the age of 2.5 years in a general population screening and then received a diagnosis of autism spectrum disorder were enrolled in an intervention program provided by Swedish habilitation services. The following interventions were available: a comprehensive intervention based on Applied Behavior Analysis - Intensive Learning (IL) - in two settings, which included home- and preschool-based (IL Regular) and only home-based (IL Modified) and eclectic interventions.

Results: There was considerable variability in terms of outcome, but intervention group status was not associated with any of the chosen outcome variables.

Conclusion: The main finding was that the type of intervention was not critical for outcome of adaptive or global functioning. The variability in outcome demonstrates the need for continuous assessments and evaluation of the child's function and behavior throughout the intervention period.
\end{abstract}

Keywords: autism spectrum disorder, preschool children, early intervention, ABA, cognitive function, follow-up

\section{Introduction}

Autism spectrum disorder (ASD) comprises conditions characterized by social communication impairments and behavioral restriction, ${ }^{1,2}$ which appear early in childhood and usually persist during life. There is general agreement that ASD should be identified early so that adequate intervention can be initiated. ${ }^{3-5}$ In 2007, the American Academy of Pediatrics issued a policy statement strongly recommending universal screening for autism in children by the age of 24 months. ${ }^{6}$ The rationale of the US Academy of Pediatrics recommendation about general autism screening is to establish a coordinated and effective organization of services. When establishing an ASD diagnosis, medical/genetic counseling, medical management, family support, educational interventions, and guidance to appropriate intervention programs for the child should be initiated. ${ }^{6}$ However, in a UK statement by the National Health Service, there is a recommendation against universal screening. ${ }^{7}$ Allaby and Sharma ${ }^{8}$ discussed many concerns against early screening for ASD; the main argument being that it is still unknown if interventions after early screening lead to significant improvements later in childhood, or greater independence and improved vocational and social functioning in adulthood. In addition, the U.S. Preventive Services Task Force ${ }^{9}$ concludes that there 
is insufficient evidence to assess the benefits of screening for ASD in children, that evidence is lacking for the population to be screened, and that the balance of benefits and harms cannot be determined.

The most disseminated comprehensive intervention programs for children with autism are based on Applied Behavior Analysis (ABA). ${ }^{10-13}$ The core elements of ABA include strategies such as discrete trail training, use of 1:1 adult to child interaction, implementation in either home or school settings for a range of 20 to 40 hours/week. ${ }^{14}$

ABA is a frequently used intervention program within the Swedish Child Habilitation Services. The Early Start Denver Model integrates ABA with developmental and relationship-based approaches for improving cognitive and adaptive behavior ${ }^{15,16}$ and emphasizes the role of parents in the intervention program. This model has given important ideas to the Swedish Child Habilitation Services. ${ }^{17}$ Furthermore, the Picture Exchange Communication System (PECS), based on ABA, as an augmentative communication (ACC) system is frequently used in children with autism. ${ }^{18}$

Another early intervention program focusing on autism, centered on structured education, is the Treatment and Education of Autistic and related Communication handicapped CHildren subsumed under the TEACCH acronym. ${ }^{19}$ Up until recently, this was probably the most widely disseminated educational program for children, adolescents, and adults with autism and related social communication disorders.

Due to the heterogeneity of ASDs, ${ }^{20}$ several factors will affect outcome. Ben-Itzchak et $\mathrm{al}^{21}$ studied an Israeli research cohort of 46 children with ASD - without genetic syndromes and with different cognitive levels - who had received centerbased intensive behavioral intervention (ABA) over a period of 2 years. When the impact of baseline cognitive ability on outcome trajectories was assessed, significant gains in adaptive skills were found only in the group of children with ASD and high cognitive scores (DQ $\geq 70$ ). Also, a Swedish study evaluating the outcome of early intensive behavioral intervention found that the subgroup of ASD without intellectual disability had a better 2-year outcome with regard to adaptive functioning compared to the group with ASD and concomitant intellectual disability. ${ }^{22}$ There was no association with intervention intensity either in this group or in the group with lower IQ.

Although randomized controlled trials are generally the most optimal method to evaluate treatment effects, there is also a need for outcome studies based on representative samples, studied in naturalistic settings. ${ }^{23,24}$
The aim of this prospective naturalistic study was to evaluate outcome in terms of adaptive behavior and global functioning. Another aim was to analyze the association with IQ and type of intervention (provided in a naturalistic setting within Child Habilitation Services) in a cohort of children who had been diagnosed with ASD after screening at the age of $\sim 2.5$ years and who had received 2 years of one of three different types of intervention.

\section{Material and methods Study area and original study cohort}

The study area was the city of Gothenburg with $\sim 500,000$ inhabitants and about 6,000 births per year. Since 2009, an ASD screening program has been implemented at all Children's Healthcare Centers (CHC) in Gothenburg. The screening takes place at the same time as a speech and language screening at 2.5 years of age. ${ }^{25}$ Between 2009 and 2011, a total of 134 children younger than 4 years with suspected ASD were referred after such screening to the Child Neuropsychiatric Clinic (CNC) in Gothenburg for further ASD assessment (assessment 1= T1). Parents of 129 (102 boys, 27 girls) of the 134 children provided written informed consent to have their child participate in the assessment program at CNC. In addition to a broad multidisciplinary assessment, including cognitive/intellectual tests, ${ }^{26}$ they had all been assessed by the Autism Diagnostic Observation Schedule-Generic. ${ }^{27}$ For $72 \%$ of the children $(93 / 129)$, at least one parent had been interviewed using the Diagnostic Interview for Social and Communication Disorders. ${ }^{28,29}$ One hundred of the children met criteria for a diagnosis of ASD at T1, and were referred to a habilitation center in Gothenburg for intervention. ${ }^{26}$ A vast majority of these children received intervention at the habilitation center, either an intensive program, Regular Intensive Learning (Regular IL) or Modified Intensive Learning (Modified IL), or a non-intensive, eclectic program.

\section{Present study group}

Out of the 100 children referred to a habilitation center, 71 children (15 girls, 56 boys) had received interventions and participated in a follow-up at CNC after 2 years. Two families had moved from Gothenburg, two families did not take part in any of the intervention programs, five families declined contact with the habilitation center, and 20 families declined the 2-year follow-up at CNC.

No child was excluded from the intervention or follow-up because of low IQ or presence of comorbidities, or the parent(s) speaking another native language other than 
Swedish. Of the 71 children, 21 had average intellectual functioning (AIF) (IQ $\geq 85$ ), 20 had borderline intellectual functioning (BIF) (IQ =71-84), and 30 had intellectual developmental disorder (IDD) (IQ $\leq 70)^{1,2}$ according to psychometric test results. ${ }^{30-32}$

\section{Interventions given at the habilitation center}

The habilitation professionals are organized as multidisciplinary teams consisting of several clinical professionals: neuropediatrician, psychologist, social worker, occupational therapist, physiotherapist, speech and language pathologist, nurse, and dietician. All professionals had prior experience working with typically developing children and long experience of working with parents and children with ASD. The teams offer different types and intensities of interventions. All interventions in the study were implemented according to conjoint parent request and professional assessments.

\section{Introduction program for parents}

An "introduction program" was offered at the habilitation centers, within 3 months after referral, to all parents with a child diagnosed with ASD. This program included three or four group sessions of 3 hours each. The parents were given information about ASD, the cognitive deficits characterizing $\mathrm{ASD}$, and an overall description of treatment and interventions for children with ASD. Information was also given about social services support that parents could apply for.

\section{Comprehensive programs}

The specific comprehensive intervention program, based on ABA, used in the western parts of Sweden was the "Intensive Learning for young children with autism". ${ }^{33}$ This manual-based program provides a curriculum of imitation as learning-how-to-learn-skills, social skills, play, communication, language, and academic skills. ${ }^{34}$ The supervisors are responsible for creating individual plans based on each student's unique individual needs ${ }^{34}$ and use written exercises to support parents and preschool teachers. Data collection was made weekly with a view to increase naturalistic training possibilities and the child's need of support in 1:1 training. Protocols were used to control hours of training, based on individual plans and goals, and defined in collaboration with parents and preschool teachers. The intervention was planned and implemented for 2 years per child. IL was used in two different settings. The first was the regular form, which was implemented for parallel use at home and at the child's preschool. This program included sessions twice a month with supervisors, and the "1:1 intervention" included 10 hours at home and 15 hours at preschool/week (total 25 hours/ week). The second setting was the modified form, which was implemented only at home and offered sessions once a month with supervisors. The "1:1 intervention" included 10 hours at home/week (total 10 hours/week).

\section{Eclectic interventions}

All eclectic interventions include strategies that are designated to be used in typical interactions and occur in natural settings, routines, and activities. ${ }^{35}$ Mandell and Stahmer $^{36}$ drew attention to the need to regard eclectic practice as a systematically determined process based on child and teaching characteristics, and careful, ongoing assessment rather than simply combining multiple methods into one program. The eclectic interventions in this study were planned and evaluated over a 2-year period with parents, and each child was only offered one parent-implemented intervention at the same time. Types of eclectic interventions used were PECS $^{18}$ and the ComAlong program, which is a Swedish parent-implemented Functional Communication Training, ${ }^{37}$ using alternative and augmentative communication. Fidelity and implementation of ComAlong were evaluated through videos of the parents' homework with their children. Another program used was TEACCH. ${ }^{19}$ This latter program is mainly used for modification or manipulation of the environment to affect the child's behavior with structured work systems and visual strategies (Table 1).

The Regular IL group consisted of 31 children (4 girls, 27 boys) with a chronological mean age of 35.2 months and a mean cognitive score of IQ 78.0.

The Modified IL group consisted of 19 children ( 7 girls, 12 boys) with a chronological mean age of 35.7 months and a mean cognitive score of IQ 69.0.

The Eclectic group consisted of 21 children (4 girls, 17 boys) with a chronological age of 37.4 months and mean cognitive score of IQ 82.0.

All details, such as sex, age, intellectual levels of the children, and parents' country of birth at T1 are arranged according to the three invention groups in Table 2 .

\section{Cooperation with preschools}

The preschools involved in the study usually had 18-24 children (aged 12-60 months) in each group. Each such group had three preschool teachers. The preschool authorities in Gothenburg decided about the need of assistance from habilitation services for children with developmental disorders, such as ASD. 
Table I Description and content of the intervention programs

\begin{tabular}{|c|c|c|c|}
\hline Description & $\begin{array}{l}\text { Regular Intensive Learning for } \\
\text { young children with autism }\end{array}$ & $\begin{array}{l}\text { Modified Intensive Learning } \\
\text { for young children with autism }\end{array}$ & $\begin{array}{l}\text { Eclectic } \\
\text { interventions }\end{array}$ \\
\hline Type of intervention program & Comprehensive program & Comprehensive program & $\begin{array}{l}\text { Focused interventions } \\
\text { to promote single skills }\end{array}$ \\
\hline Manual-based program & $\begin{array}{l}\text { Intensive learning for young children } \\
\text { with autism }{ }^{33}\end{array}$ & $\begin{array}{l}\text { Intensive learning for young } \\
\text { children with autism } \\
33\end{array}$ & $\begin{array}{l}\text { PECS, }{ }^{18} \text { ComAlong, } \\
\text { TEACCH }\end{array}$ \\
\hline Theoretical framework & $\begin{array}{l}\text { ABA } \\
\text { Developmental psychology }\end{array}$ & $\begin{array}{l}\text { ABA } \\
\text { Developmental psychology }\end{array}$ & $\begin{array}{l}\text { Developmental } \\
\text { psychology }\end{array}$ \\
\hline Format used in training & $\begin{array}{l}\text { Incidental teaching } \\
\text { Discrete trial training } \\
\text { Typical settings }\end{array}$ & $\begin{array}{l}\text { Incidental teaching } \\
\text { Discrete trial training } \\
\text { Typical settings }\end{array}$ & $\begin{array}{l}\text { Typical interactions } \\
\text { in natural settings, } \\
\text { routines, and activities }\end{array}$ \\
\hline Intensity per week & 20-25 hours/week & 5-10 hours/week & Various \\
\hline Supervisor sessions & Two sessions/month & One session/month & Various \\
\hline Supervisor strategy & $\begin{array}{l}\text { Modeling to parents and preschool staff } \\
\text { Written exercises }\end{array}$ & $\begin{array}{l}\text { Modeling to parents } \\
\text { Written exercises }\end{array}$ & $\begin{array}{l}\text { Directly delivered to } \\
\text { the child }\end{array}$ \\
\hline Parents' participation required & Yes & Yes & Yes \\
\hline Preschool participation required & Yes & No & Not regularly \\
\hline
\end{tabular}

Abbreviations: ABA, applied behavior analysis; PECS, Picture Exchange Communication System; TEACCH, Treatment and Education of Autistic and related Communication handicapped CHildren.

\section{Follow-up assessments at the clinic}

All the children were assessed at $\mathrm{CNC}$ once again 2 years after their first assessment with regard to autistic behavior/ ASD, intellectual, adaptive, and global functioning. The same tests used at $\mathrm{T} 1$ were used and professionals with long experience of assessing children with ASD administrated tests according to standard procedures. All the professionals were blinded to the type of intervention received by the children.

The ASD follow-up assessment encompassed clinically validated instruments: the Diagnostic Interview for Social and Communication Disorders, ${ }^{28,29}$ the Autism Diagnostic Interview, ${ }^{38}$ and the Autism Diagnostic Observation Schedule. ${ }^{27}$ Intellectual level was assessed according to at least one of the following: Griffiths' test, ${ }^{30}$ Wechsler Preschool and Primary Scale of Intelligence-III, ${ }^{31}$ or MerrillPalmer-Revised Scales of Development. ${ }^{32}$

\section{Outcome measures}

Adaptive functions were measured with the Vineland Adaptive Behavior Scale, Second Edition (VABS-II), ${ }^{39}$ which is an interview-based evaluation of the child's adaptive skills. A psychologist conducted this interview with one or both parents. All the results are given as standard scores.

The Children's Global Assessment Scale (C-GAS) ${ }^{40,41}$ is a clinical global judgment of the child's total situation or overall severity of impairment, not just one particular symptom. The scale was originally developed for use in 4- to 20-year-old children and adolescents, but it has since been adapted for younger children by the $\mathrm{CNC}$ assessment team. ${ }^{26}$ This scale used normed scores.

\section{Statistics}

The distribution of intellectual levels in the three intervention groups (Regular IL, Modified IL, and Eclectic groups)

Table 2 Three intervention groups in relation to sex, age, and intellectual levels of the children at TI and parents' country of birth

\begin{tabular}{|c|c|c|c|c|}
\hline Background data & $\begin{array}{l}\text { Regular IL group } \\
\mathrm{N}=3 \text { I }\end{array}$ & $\begin{array}{l}\text { Modified IL group } \\
\mathrm{N}=19\end{array}$ & $\begin{array}{l}\text { Eclectic group } \\
N=21\end{array}$ & Test \\
\hline Sex & 4 girls, 27 boys & 7 girls, 12 boys & 4 girls, 17 boys & $\chi_{2}^{2}=1.63, P=0.443$ \\
\hline \multirow[t]{3}{*}{ Age at TI } & $M=35.2$ months & $M=35.7$ months & $M=37.4$ months & $F_{2,68}<1$ \\
\hline & $\mathrm{Cl}=32.7 \mathrm{I}-37.6 \mathrm{I}$ & $\mathrm{Cl}=32.55-38.82$ & $\mathrm{Cl}=34.62-40.23$ & $\eta^{2}=0.01$ \\
\hline & $S D=6.68$ & $S D=6.5 \mathrm{I}$ & $S D=6.16$ & \\
\hline \multirow[t]{3}{*}{ IQ at TI } & $M=78$ & $M=69$ & $M=82$ & $F_{2,68}=2.90$ \\
\hline & $\mathrm{Cl}=72.5 \mathrm{I}-83.67$ & $\mathrm{Cl}=6 \mathrm{I} . \mid 4-77.81$ & $\mathrm{Cl}=71.59-91.68$ & $P=0.062$ \\
\hline & $S D=14.98$ & $S D=|6.2|$ & $S D=20.84$ & $\eta^{2}=0.08$ \\
\hline Both parents born in Sweden & $12(38.7 \%)$ & $5(26.3 \%)$ & $10(47.6 \%)$ & $\chi_{2}^{2}=2.89, P=0.236$ \\
\hline One parent born in Sweden & $6(19.4 \%)$ & $5(26.3 \%)$ & $2(9.5 \%)$ & $\chi_{2}^{2}=2.00, P=0.368$ \\
\hline Both parents born in other countries & $13(42 \%)$ & $9(47.4 \%)$ & $9(42.9 \%)$ & $\chi_{2}^{2}=0.806, P=0.369$ \\
\hline
\end{tabular}

Abbreviations: $\mathrm{Cl}$, 95\% confidence interval; IL, Intensive Learning; M, mean; SD, standard deviation; TI, assessment I. 
was examined with chi-square test. As main outcomes measures, adaptive composite score and C-GAS before vs after treatment were used as dependent variables in two separate mixed analysis of variance (ANOVA) and intellectual level as independent variables in the intervention groups.

\section{Ethics}

The Regional Ethics Committee of the Medical Faculty, University of Gothenburg, Sweden, approved the study with registration number 494-08. Informed consent was obtained from at least one of the parents or responsible caretaker for each child.

\section{Results}

\section{Introduction program to parents}

One or both parents of 47 of the 71 children (65\%) completed the "introduction program"; 22 of the 31 parents (70\%) in the Regular IL group, 11 of the 19 parents (57\%) in the Modified IL group, and 14 of the 21 parents (67\%) in the Eclectic intervention group participated. This was mainly due to the following reasons: 1) parents having already attended the program with an elder sibling with ASD or 2) parents had chosen to receive individual information about ASD.

\section{IL programs}

Fifty children (70\%) participated in the IL programs: 31 $(44 \%)$ in the regular IL and $19(27 \%)$ children in a modified version of IL.

\section{Eclectic interventions}

The main types of eclectic programs described were given to 21 children and parents. Most children had been offered more than one intervention (mean [M] 2.76, standard deviation [SD] 1.48): ComAlong (16 children), PECS (four children), and TEACCH-based strategies (ten children). Six children participated in a playgroup, and three children joined a communication and motor group with other children.

\section{Distribution of intellectual levels in the intervention groups}

A cross-tabulation between intellectual level at T1 (IDD, BIF, AIF) and intervention (Regular IL, Modified IL, and Eclectic intervention) revealed a significant relation between intellectual level and type of intervention $\left(\chi_{4}^{2}=11.99, P=0.017\right)$. Children with IDD were overrepresented in the Modified IL group ( $\mathrm{n}=12$, adjusted standardized residual $=2.2$ ), children with BIF were overrepresented in the Regular IL group $(\mathrm{n}=13$, adjusted standardized residual $=2.3)$, and children with AIF were overrepresented in the Eclectic intervention group ( $n=11$, Adjusted standardized residual =2.7) (Table 2). The intellectual level/intervention group combination with the least children were BIF/Eclectic intervention and AIF/Modified IL with only three children in each. Combining BIF and AIF into one group to get groups of IDD vs BIF + AIF resulted in a weaker relationship between intellectual level and intervention $\left(\chi_{2}^{2}=4.67, P=0.097\right)$. The largest number of children was in the BIF + AIF/Regular IL combination $(n=20)$ and the smallest number was in the BIF + AIF/Modified IL combination $(n=7)$ and in the IDD/Eclectic combination $(n=7)$.

\section{Outcome of adaptive functioning (VABS composite scores)}

Of the 71 children, 64 children had VABS data at both T1 and T2. Despite quite large differences in cell sizes, a $2 \times 2 \times 3$ mixed ANOVA with time (before and after intervention; Table 2) as a within-subject factor, intellectual level (IDD vs BIF + AIF) and type of intervention (Regular IL, Modified IL, and Eclectic intervention) as between-subject factors, and adaptive composite score as the dependent variable was performed. Mean adaptive composite scores with $95 \%$ confidence intervals for each of the 12 investigated combinations of time $\times$ intellectual level $\times$ type of intervention are shown in Figure 1. None of the interventions increased the adaptive composite scores from T1 to T2 more than any other (for the time $\times$ type of intervention interaction $F_{2,58}=2.20, P=0.120$, $\left.\eta_{\text {partial }}^{2}=0.071\right)$ nor did the adaptive composite scores increase significantly from $\mathrm{T} 1$ to $\mathrm{T} 2$ in general $\left(F_{1,58}<1\right.$ for the main effect of time). Figure 1 shows that within each of the two groups of different intellectual level, there is considerable overlap between all confidence intervals. The only effect that became significant was the main effect of intellectual level $\left(F_{1,58}=11.86, P=0.001, \eta_{\text {partial }}^{2}=0.170\right)$. Children with BIF or AIF had significantly higher adaptive composite scores compared to children with IDD $(\mathrm{M}=78.08, \mathrm{SD}=8.07$ for children with BIF or AIF vs $\mathrm{M}=69.63, \mathrm{SD}=9.79$ for children with IDD; Figure 1).

\section{Variance of adaptive functioning (VABS composite scores)}

The mean of adaptive composite scores did not change after intervention, but the variance in variables did; as can be seen in Figure 1, all confidence intervals are larger at T2 than at T1. This was confirmed by Levene's test for equality of variances showing a significant increase of variance in adaptive composite scores after intervention: $F_{1,133}=19.25$, $P<0.001, \mathrm{SD}_{\mathrm{T} 1}=8.49, \mathrm{SD}_{\mathrm{T} 2}=14.00$. 


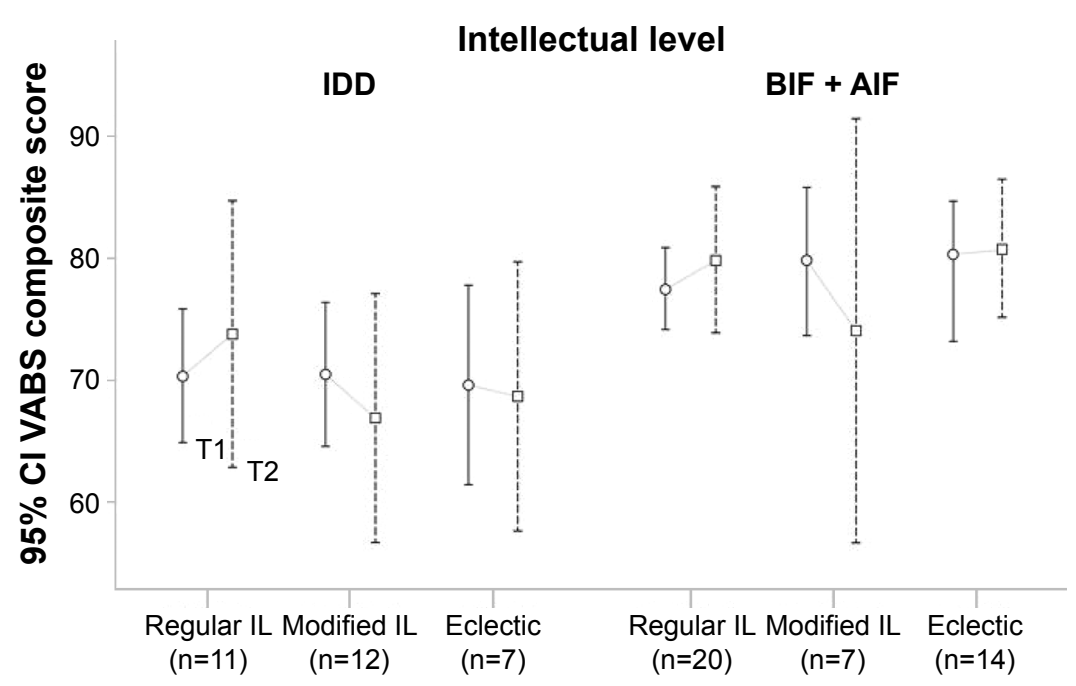

Figure I 95\% confidence intervals for the mean change in VABS composite scores between TI and T2 for the three intervention groups and for the two cognitive levels, respectively.

Abbreviations: AIF, average intellectual functioning; BIF, borderline intellectual functioning; $\mathrm{Cl}$, confidence interval; IDD, intellectual developmental disorder; IL, Intensive Learning; VABS, Vineland Adaptive Behavior Scale; TI, assessment I; T2, assessment 2.

\section{Outcome of global functioning (C-GAS)} A $2 \times 2 \times 3$ mixed ANOVA with time (before and after intervention) as a within-subject factor, intellectual level (IDD vs BIF + AIF) and type of intervention (Regular IL, Modified IL, and Eclectic intervention) as between-subject factors, and C-GAS score as the dependent variable was performed. Mean C-GAS with $95 \%$ confidence intervals for each of the 12 investigated combinations of time $\times$ intellectual level $\times$ type of intervention is shown in Figure 2. A main effect of time $\left(F_{1,65}=4.00\right.$, $\left.P=0.050, \eta_{\text {partial }}^{2}=0.058\right)$ showed that C-GAS in the children in general increased from $\mathrm{T} 1(\mathrm{M}=40.04, \mathrm{SD}=9.31)$ to $\mathrm{T} 2$ $(\mathrm{M}=43.66, \mathrm{SD}=12.10)$. As can be seen in Figure 2, with the exception of children in the Modified IL group with BIF or
AIF, for all three interventions and both intellectual levels, C-GAS increased in the children from $\mathrm{T} 1$ to $\mathrm{T} 2$. There was, however, no time $\times$ type of intervention interaction $\left(F_{2,65}<1\right)$; so, there was no evidence for any particular intervention to have increased C-GAS than the rest of the intervention. Finally, there was a main effect of intellectual level. The children with BIF or AIF $(\mathrm{M}=45.18, \mathrm{SD}=6.98)$ had significantly higher score on C-GAS than the children with IDD $(\mathrm{M}=37.30$, $\mathrm{SD}=10.21 ; F_{1,65}=10.01, P=0.002, \eta_{\text {partial }}^{2}=0.133$; Figure 2 ).

\section{Variance of global functioning (C-GAS)}

As for the adaptive composite scores, the variance of the C-GAS scores increased from T1 to T2 (Figure 2). However,

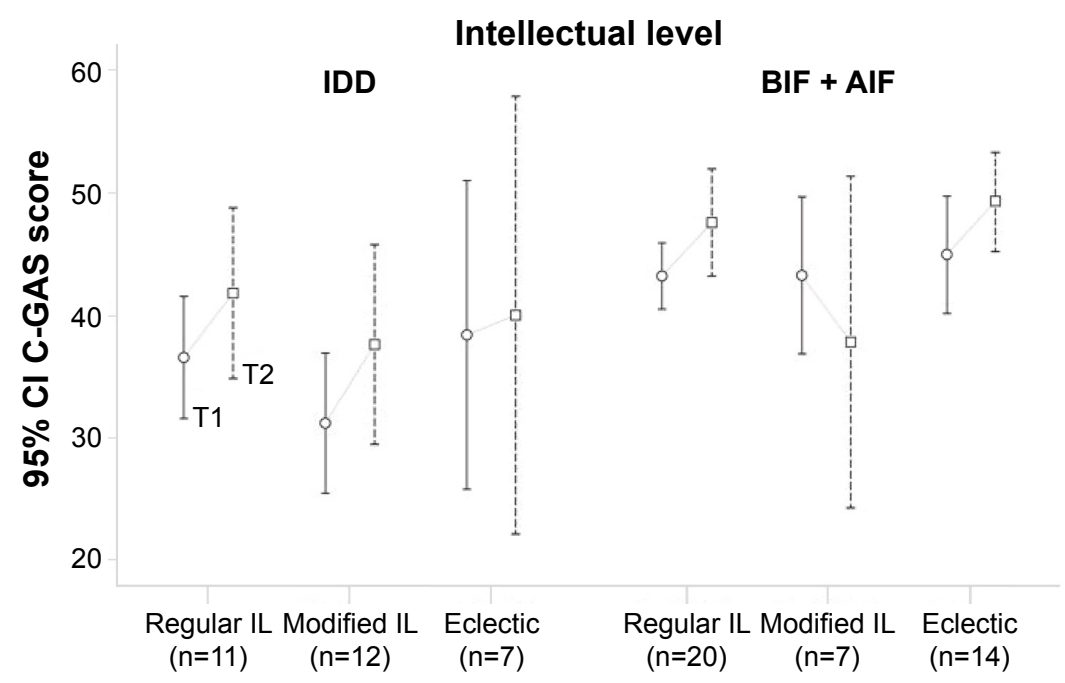

Figure $295 \%$ confidence intervals for the mean change in Global functioning scores between TI and T2 for the three intervention groups and for the two cognitive levels, respectively.

Abbreviations: AIF, average intellectual functioning; BIF, borderline intellectual functioning; C-GAS, Children's Global Assessment Scale; Cl, confidence interval; IDD, intellectual developmental disorder; IL, Intensive Learning; TI, assessment I; T2, assessment 2. 
the increase was not significant, according to Levene's test for equality of variances $\left(F_{1,140}=12.85, P=0.094, \mathrm{SD}_{\mathrm{T} 1}=9.31\right.$, $\mathrm{SD}_{\mathrm{T} 2}=12.10$ ).

\section{ASD diagnostic stability between TI and T2}

Five of the 71 children (7\%) no longer met criteria for ASD at T2. Three of these children were in the Regular IL group and one child each in the two other groups.

\section{Discussion}

All the children in the present study had screened positive for ASD in a general population surveillance program at the age of $\sim 2.5$ years, and the study group can be considered representative of children with an early diagnosis of ASD. The study had the advantages of ecological validity ${ }^{23}$ and consisted of the typical clinical process where cases referred from $\mathrm{CHC}$ had a comprehensive assessment and had been offered intervention within a short period from their first visit to the habilitation center.

The main finding of this study was that the type of intervention was not critical for outcome of adaptive and global functioning according to the results of Vineland adaptive composite score and C-GAS. Thus, treatment based on ABA did not differ from other types of interventions provided by the habilitation center or preschool. This is in accordance with the finding from a previous Swedish study, ie, type and intensity of intervention were not decisive for adaptive functioning outcome. ${ }^{22}$ However, this is somewhat in contrast to a review by Leaf et $\mathrm{a}^{34}$ highlighting the effects of early intensive behavioral intervention with regard to meaningful outcomes.

Our results differ from studies by Howard et $\mathrm{al}^{42}$ comparing early $\mathrm{ABA}$ and eclectic interventions, reporting $\mathrm{ABA}$ to produce substantial improvements in young children with autism compared to common eclectic interventions, even when intensive. However, our findings accord with conclusions put forward by Odom et al in their review. ${ }^{43}$ They reported a comparison of intensive behavioral treatment programs with eclectic interventions and concluded that eclectic programs had a positive impact on development, learning, and life outcomes in children and youth with autism when being well implemented. The recent large systematic review, including 65 unique studies of behavioral intervention for children with ASD, by Weitlauf et al ${ }^{44}$ summarized that a growing evidence base suggests that behavioral interventions are associated with some positive outcomes in children with ASD; however, they also suggested that there is a need for studies of interventions across settings and with continued improvements in methodological rigor. The Cochrane report by Reichow et $\mathrm{al}^{14}$ on early intensive behavioral intervention for young children with ASD emphasized the importance of different designs when studying outcomes, and that randomized controlled trials may not always be the optimal, or only, design (also refer Fernell et $\mathrm{al}^{24}$ for further details).

ASDs are complex and heterogeneous disorders and in the majority of children other coexisting developmental disorders are present, ie, "autism plus", ${ }^{45}$ and sometimes these disorders are of greater importance for prognosis than the ASD per se. This means that outcome will be dependent on the total clinical presentation, including intellectual level, ${ }^{21,46,47}$ and on the underlying medical etiology. The diagnostic complexities were discussed by Volkmar and Reichow ${ }^{48}$ who emphasized that even though the evidence-based research on treatment has increased in this young age group, the state of knowledge is limited.

Although the mean adaptive composite score did not change significantly between $\mathrm{T} 1$ and $\mathrm{T} 2$, the variance increased significantly. This probably reflects that gain and loss of adaptive skills varied considerably between children at the follow-up. This finding underscores the need for regular monitoring of the child's functioning and developmental progress/ no progress during the intervention period and the necessity to consider a change or modification of the program in use.

Five of the children ( $7 \%$ of the total group) no longer met criteria for ASD at the 2-year-follow-up. However, it is important to note that these children were not necessarily less impaired than those who still met such criteria. ${ }^{49}$ To minimize the stress of parents and children, it would be preferable to give children with developmental disorder access to clinical support for long periods regardless of diagnosis affiliation.

There are considerable clinical experiences and research supporting the importance of early identification, information to parents and preschool staff, and the need for appropriate interventions in all children with ASD to provide support to children and families, ie, an autism-friendly environment. ${ }^{50,51}$

In our original cohort of children assessed at $\mathrm{CNC}$ after their 2.5-year screening at $\mathrm{CHC}$, the group of children not meeting full criteria for ASD, but who had other Early Symptomatic Syndromes Eliciting Neurodevelopmental Clinical Examinations problems, ${ }^{52}$ did not get access to habilitation services. These children have also been followed up clinically and a substantial number have been found to meet ASD criteria at their T2 assessment (data will be detailed in a forthcoming study). This highlights the importance of providing all children with developmental disorders/problems/Early Symptomatic Syndromes Eliciting Neurodevelopmental Clinical Examinations problems with 
targeted interventions by a multi-professional team, along with clinical and medical follow-up, first of all to school age but also into school age.

\section{Strengths and limitations}

The strengths of this study lie in the representativeness of the sample that was not selected, and that the study was conducted in a naturalistic setting. Moreover, all the children were assessed by the same research team using the same test methods at both T1 and T2, and the research group was blinded to the type of intervention given within the habilitation services. The limitations are mainly due to the relatively small intervention groups, attrition, and some parents declining intervention from habilitation services and/or declining the follow-up assessment. Other limitations are that the children were not randomized to the type of intervention, but the intervention was implemented according to clinical considerations and to parents' and professionals' assessment of the child's needs. Moreover, the therapists, ie, licensed child psychologists and licensed speech and language pathologists at the habilitation centers, provided interventions in a naturalistic clinical setting and there was no procedure in place to specifically assess treatment integrity.

\section{Conclusion}

The present study of children, diagnosed with ASD after screening at the age of 2.5 years and assessed before and after intervention, showed a wide variability in terms of outcomes of adaptive and global functioning. Intervention group status was not associated with any of the chosen outcome variables. The variability in outcomes demonstrates the need for continuous assessments and evaluation of the child's function and behavior throughout the intervention period, and that programs and methods may need modification.

\section{Acknowledgments}

The authors are grateful to the children and their parents for participating in the study. They are also indebted to the colleagues at CNC and Health \& Habilitation, Gothenburg, Sweden, for their help in making the study possible. The study received financial support from The Health \& Medical Care Committee of the Regional Executive Board, Region Västra Götaland (BSJ).

\section{Disclosure}

The authors report no conflicts of interest in this work.

\section{References}

1. American Psychiatric Association (APA). Diagnostic and Statistical Manual of Mental Disorders. 4th ed. Washington (DC): American Psychiatric Association; 2000.

2. American Psychiatric Association (APA). Diagnostic and Statistical Manual of Mental Disorders. 5th ed. Washington (DC): American Psychiatric Association; 2013.

3. Eikeseth S. Outcome of comprehensive psycho-educational interventions for young children with autism. Res Dev Disabil. 2009;30(1): 158-178.

4. Fernell E, Eriksson MA, Gillberg C. Early diagnosis of autism and impact on prognosis: a narrative review. Clin Epidemiol. 2013;5:33-43.

5. Webb SJ, Jones EJ, Kelly J, Dawson G. The motivation for very early intervention for infants at high risk for autism spectrum disorders. Int J Speech Lang Pathol. 2014;16(1):36-42.

6. Johnson CP, Myers SM; American Academy of Pediatrics Council on Children With Disabilities. Identification and evaluation of children with autism spectrum disorders. Pediatrics. 2007;120(5):1183-1215.

7. The UK NSC recommendation on Autism screening in children, 2012. Available from: http://www.screening.nhs.uk/autism. Accessed March 1, 2016.

8. Allaby M, Sharma M. Screening for autism spectrum disorders in children below the age of 5 years. A Draft Report for the UK National Screening Committee. Solutions for Public Health, NHS; 2011.

9. Autism Spectrum Disorder in Young Children: Screening. U.S. Preventive Services Task Force, 2016. Available from: http://www.uspreventiveservicestaskforce.org/Page/Document/ UpdateSummaryFinal/autism-spectrum-disorder-in-young-childrenscreening?ds $=1 \& \mathrm{~s}=$ autism $\% 20$ spectrum $\% 20$ disorder $\% 20 \mathrm{in} \% 20$ young\%20children\%20screening. Accessed March 1, 2016.

10. Maurice C, Green G, Luce SC. Behavioural Intervention for Young Children With Autism: A Manual for Parents and Professionals. Austin (TX): Pro-Ed; 1996.

11. Leaf R, McEachin J. A Work in Progress. New York (NY): DRL Books; 1999.

12. Fovel JT. The ABA Program Companion: Organizing Quality Programs for Children With Autism and PDD. New York: DRL Books; 2002.

13. Lovaas OI. Teaching Individuals With Developmental Delays; Basic Intervention Techniques. Austin (TX): PRO-ED; 2002.

14. Reichow B, Barton EE, Boyd BA, Hume K. Early intensive behavioral intervention (EIBI) for young children with autism spectrum disorders (ASD). Cochrane Database Syst Rev. 2012;10:CD009260.

15. Vismara LA, Colombi C, Rogers S. Can one hour per week therapy lead to lasting changes in young children with autism? Autism. 2009; 13(1):93-115.

16. Dawson G, Rogers S, Munson J, et al. Randomized, controlled trial of intervention for toddlers with autism: the Early Start Denver Model. Pediatrics. 2010;125(1):e17-e23.

17. Mångsidiga intensiva insatser för barn med autism i förskoleåldern, 2012 [Interventions for children with autism in the preschool age]. Available from: http://www.habiliteringschefer.se/ebh/autism/autism. html. Accessed March 1, 2016. Swedish.

18. Frost L, Bondy A. The Picture Exchange Communication System training manual. 2nd ed. Newark (DE): Pyramid Educational Products; 2002.

19. Mesibov GB, Shea V. The TEACCH program in the era of evidencebased practice. J Autism Dev Disord. 2010;40(5):570-579.

20. Coleman M, Gillberg C. The Autisms. Oxford: Oxford University Press; 2012.

21. Ben-Itzchak E, Watson LR, Zachor DA. Cognitive ability is associated with different outcome trajectories in autism spectrum disorders. J Autism Dev Disord. 2014;44(9):2221-2229.

22. Fernell E, Hedvall $\AA$, Westerlund J, et al. Early intervention in 208 Swedish preschoolers with autism spectrum disorder. A prospective naturalistic study. Res Dev Disabil. 2011;32(6):2092-2101.

23. Schmuckler MA. What is ecological validity? A dimensional analysis. Infancy. 2001;2:419-436. 
24. Fernell E, Wilson P, Hadjikhani N, et al. Screening, intervention and outcome in autism and other developmental disorders: the role of randomized controlled trials. J Autism Dev Disord. 2014;44(8):2074-2076.

25. Nygren G, Sandberg E, Gillstedt F, Ekeroth G, Arvidsson T, Gillberg C. A new screening programme for autism in a general population of Swedish toddlers. Res Dev Disabil. 2012;33(4):1200-1210.

26. Kantzer AK, Fernell E, Gillberg C, Miniscalco C. Autism in community pre-schoolers: developmental profiles. Res Dev Disabil. 2013; 34(9):2900-2908.

27. Lord C, Risi S, Lambrecht L, et al. The Autism Diagnostic Observation Schedule-Generic: a standard measure of social and communication deficits associated with the spectrum of autism. J Autism Dev Disord. 2000;30(3):205-223.

28. Wing L, Leekam SR, Libby SJ, Gould J, Larcombe M. The Diagnostic Interview for Social and Communication Disorders: background, inter-rater reliability and clinical use. J Child Psychol Psychiatry. 2002;43(3):307-325.

29. Nygren G, Hagberg B, Billstedt E, Skoglund A, Gillberg C, Johansson M. The Swedish version of the Diagnostic Interview for Social and Communication Disorders (DISCO-10). Psychometric properties. J Autism Dev Disord. 2009;39(5):730-741.

30. Alin-Åkerman B, Nordberg L. Griffiths' Developmental Scales I and II. Stockholm: Hogrefe Psykologiförlaget AB; 1980.

31. Wechsler D. Wechsler Preschool and Primary Scale of Intelligence, revised, Swedish version. Stockholm: Hogrefe Psykologiförlaget AB; 2004.

32. Roid GH, Sampers JL. Merrill-Palmer Revised Scales of Development. Swedish version. Stockholm: Hogrefe Psykologiförlaget AB; 2005.

33. Spjut Jansson B, Lindahl U, Nilsson Rutberg M. Manual for Intensivinlärning för små barn med autism [Manual for Intensive learning for young children with autism]. Göteborg: Habilitering \& Hälsa; 2011. Swedish.

34. Leaf JB, Leaf R, McEachin J, et al. Applied behaviour analyses is a science and, therefore, progressive. J Autism Dev Disord. 2016;46(2): 720-731.

35. Odom SL, Collet-Klingenberg L, Rogers SJ, Hatton DD. Evidencebased practices in interventions for children and youth with autism spectrum disorders. Prev Sch Fail. 2010;54(4):275-282.

36. Mandell DS, Stahmer AC. State infant/toddler program policies for eligibility and services provision for young children with autism. Adm Policy Ment Health. 2007;34(1):29-37.

37. Thunberg G, Carlstrand A, Claesson B, Rensfeldt Flink A. KomIgången föräldrakurs om kommunikation och kommunikationsstöd. Kursbok [GetStarted: a parenting course on communication and communication support: textbook]. Göteborg: Habilitering \& Hälsa; 2011. Swedish.

38. Lord C, Rutter M, Le Couteur A. Autism Diagnostic InterviewRevised - a revised version of a diagnostic interview for caregivers of individuals with possible pervasive developmental disorders. J Autism Dev Disord. 1994;24(5):659-685.
39. Sparrow SS, Cichetti DV, Balla DA. Vineland Adaptive Behaviour Scales. 2nd ed. Circle Pines (MN): American Guidance Service; 2005.

40. Schorre BE, Vandvik IH. Global assessment of psychosocial functioning in child and adolescent psychiatry. A review of three unidimensional scales (C-GAS, GAF, GAPD). Eur Child Adolesc Psychiatry. 2004; 13(5):273-286.

41. Shaffer D, Gould MS, Brasic J, et al. A children's global assessment scale (CGAS). Arch Gen Psychiatry. 1983;40(11):1228-1231.

42. Howard JS, Stanislaw H, Green G, Sparkman CR, Cohen HG. Comparison of behaviour analytic and eclectic early interventions for young children with autism after three years. Res Dev Disabil. 2014; 35(12):3326-3344.

43. Odom S, Hume K, Boyd B, Stabel A. Moving beyond the intensive behavior treatment versus eclectic dichotomy: evidence-based and individualized programs for learners with ASD. Behav Modif. 2012; 36(3):270-297.

44. Weitlauf AS, McPheeters ML, Peters B, et al. Therapies for Children With Autism Spectrum Disorder: Behavioral Interventions Update [Internet]. Rockville (MD): Agency for Healthcare Research and Quality (US); 2014.

45. Gillberg C, Fernell E. Autism plus versus autism pure. J Autism Dev Disord. 2014;44(12):3274-3276.

46. Billstedt E, Gillberg IC, Gillberg C. Autism in adults: symptom patterns and early childhood predictors. Use of the DISCO in a community sample followed from childhood. J Child Psychol Psychiatry. 2007; 48:1102-1110.

47. Howlin P, Savage S, Moss P, Tempier A, Rutter M. Cognitive and language skills in adults with autism: a 40-year follow-up. J Child Psychol Psychiatry. 2014;55(1):49-58.

48. Volkmar FR, Reichow B. Infants and toddlers with autism: the promise and the challenges. Int J Speech Lang Pathol. 2014;16(1):11-14.

49. Olsson MB, Westerlund J, Lundström S, Giacobini M, Fernell E, Gillberg C. "Recovery" from the diagnosis of autism - and then? Neuropsychiatr Dis Treat. 2015;11:999-1005.

50. Ryan S, Salisbury H. 'You know what boys are like': pre-diagnosis experiences of parents of children with autism spectrum conditions. Br J Gen Pract. 2012;62(598):e378-e383.

51. Mitchell C, Holdt N. The search for a timely diagnosis: parents' experiences of their child being diagnosed with an Autistic spectrum disorder. J Child Adolesc Ment Health. 2014;26(1):49-62.

52. Gillberg C. The ESSENCE in child psychiatry: early symptomatic syndromes eliciting neurodevelopmental clinical examinations. Res Dev Disabil. 2010;31:1543-1551.
Neuropsychiatric Disease and Treatment

\section{Publish your work in this journal}

Neuropsychiatric Disease and Treatment is an international, peerreviewed journal of clinical therapeutics and pharmacology focusing on concise rapid reporting of clinical or pre-clinical studies on a range of neuropsychiatric and neurological disorders. This journa is indexed on PubMed Central, the 'PsycINFO' database and CAS,

\section{Dovepress}

and is the official journal of The International Neuropsychiatric Association (INA). The manuscript management system is completely online and includes a very quick and fair peer-review system, which is all easy to use. Visit http://www.dovepress.com/testimonials.php to read real quotes from published authors. 